integrity and stability is reliant on efficient pharmacy processes necessary to accommodate the use of new formulations for dose banding.

Disclosure of Interest: None declared

DOI: 10.1136/annrheumdis-2018-eular.1300

\section{AB1260 BASELINE CHARACTERISTICS AND PATIENT SATISFACTION DATA FROM COACH@HOME: THE GERMAN SUPPORT PROGRAM FOR PATIENTS WITH RHEUMATIC DISEASES TREATED WITH CERTOLIZUMAB PEGOL}

N. Böhme ${ }^{1}$, A.-D. Holst ${ }^{2}$, F. Dybowski ${ }^{3}$, C. Volberg ${ }^{4}$, H.-G. Pott ${ }^{5}$, U. Lendl ${ }^{6}$. ${ }^{1}$ Healthcare at Home Deutschland $\mathrm{GmbH}$, Weinheim; ${ }^{2}$ Rheumapraxis, Ludwigslust, ${ }^{3}$ Rheumapraxis Ruhr, Herne; ${ }^{4}$ Rheumatologie in Neuss, Neuss; ${ }^{5}$ Rheumatologikum Hannover, Hannover, ${ }^{6}$ UCB Pharma, Monheim, Germany

Background: Certolizumab pegol (CZP)-treated patients (pts) with rheumatoid arthritis (RA), axial spondyloarthritis (axSpA, including ankylosing spondylitis [AS] and non-radiographic [nr-] $\mathrm{axSpA}$ ), and psoriatic arthritis (PsA) may be recommended the patient-coaching program, coach@home (c@h) in Germany to manage their disease. Eight coaching calls are offered over one year, scheduled around 'critical' milestones along the therapeutic journey. These calls are made by professionally-trained nurses, who offer support and information about both the disease and its treatment with CZP

Objectives: The purpose of this observational analysis was to assess the baseline characteristics of pts subscribed to c@h, and the level of pt satisfaction with the program.

Methods: c@h was launched in ,une 2014 and is available to pts who are prescribed CZP according to the local product label. Pts must be CZP-naïve when subscribed to the program, and pt consent is required prior to subscription by the treating physician. There are no additional criteria for enrolment, although the program must be recommended to the pt by the treating physician.

Pt satisfaction was measured either at the end of the program or at discontinuation using the net promoter score (NPS), which has previously been used for this purpose. ${ }^{1}$ The NPS is derived by asking pts to state how likely it is that they would recommend c@h to others (on a 0-10 scale). Rankings of 9-10 are considered 'promoters', 7-8 'passives', and 0-6 'detractors'. Subtracting the percentage of detractors from that of promoters yields the NPS (figure 1).

Results: A cumulative total of 655 pts had been registered to the program as of 5 .ct 2017 Of the total number of reported indications $(n=683$; multiple indications per pt possible), 55.9\% were RA, $16.5 \%$ AS, $7.6 \% \mathrm{nr}$-axSpA, and $19.9 \%$ PsA. The mean age at baseline was 55 (RA), 54 (AS), 53 (nr-axSpA), and 52 (PsA), and the proportion of female pts was $80 \%, 58 \%, 65 \%$, and $69 \%$, respectively. Prior biologic DMARD exposure was $32.8 \%$.

The most common topics discussed on phone calls were therapy compliance (in 1339 calls), CZP maintenance dose (in 1333 calls) and syringe disposal (in 870 calls). The average length per call was $15.9 \mathrm{~min}$ at the end of Week 0 (total: 28 calls), and $14.0 \mathrm{~min}$ at the end of Week 52 (total: 1796 calls). A cumulative total of 272 pts had either completed the 1 year coaching period $(n=70)$ or discontinued $(n=202)$ by 28 , Sep 2017 of whom 106 rated the program. Of these, $87.5 \%$ gave promoter scores, $10.4 \%$ passive, and $3.8 \%$ detractor, yielding an NPS of 83.7 (figure 1). The program was still ongoing at the time of this data cut.
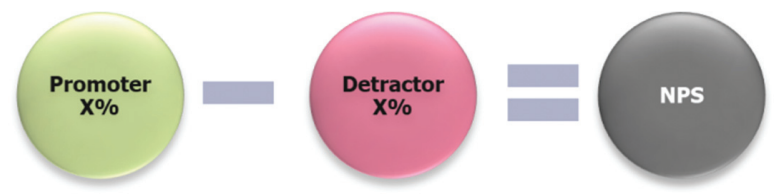

口9-10: Promoter

口7-8: Passive

口0-6: Detractor

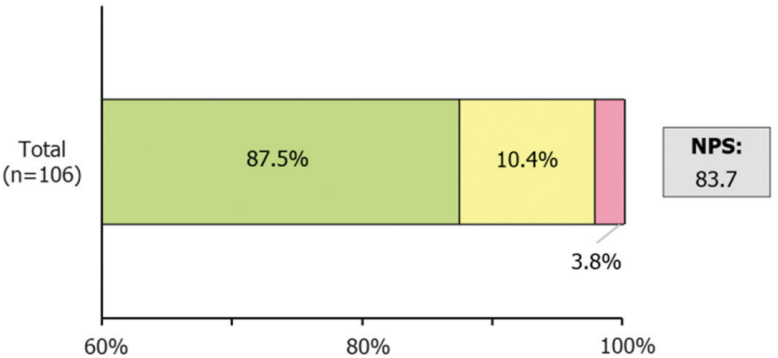

Abstract AB1260 - Figure 1. Patient ratings and Net Promoter Score for the coach@home program (as of September 2017)
Patients were asked to rate the coach@home program on a scale of 0-10, where $0=$ "I would certainly not recommend this program" and 10="I would most probably recommend this program". Scores of 9-10 were considered 'promoters', 7-8 'pas sives' and 0-6 'detractors'. Percentages shown are out of the total number of responders by the end of September 2017 ( $n=106)$. NPS: Net Promoter Score.

Conclusions: The c@h program offers guidance and support to pts treated with CZP in Germany. Feedback from pts who were willing to provide a rating indicates a high level of satisfaction with the program.

\section{REFERENCE:}

[1] Hamilton DF. Bone Joint J 2014;96-B(5):622-8.

Acknowledgements: The c@h program is performed by Healthcare@home Deutschland $\mathrm{GmbH}$, funded by UCB Pharma, led by Elke Zeise and managed by Karen Thiel and Manh Dan Nguyen. We thank the patients and their caregivers in addition to the investigators and their teams who contributed to this program. Editorial services were provided by Costello Medical.

Disclosure of Interest: N. Böhme: None declared, A.-D. Holst Grant/research support from: AbbVie, BMS, Chugai, Pfizer, Paid instructor for: BMS, Lilly, UCB Pharma, F. Dybowski: None declared, C. Volberg: None declared, H.-G. Pott Paid instructor for: Hexal, Lilly, Novartis, MSD, Speakers bureau: AbbVie, Biogen, Chugai, Roche, Pfizer, Celgene, UCB Pharma, Medac, U. Lendl Employee of: UCB Pharma

DOI: 10.1136/annrheumdis-2018-eular.1989

\section{AB1261 DEVELOPMENT OF A LOCAL NEEDS-BASED GP CURRICULUM FOR SHARED CARE IN RHEUMATOLOGY}

O. Hussein, T. Duffy. Rheumatology, Connolly Hospital Blanchardstown, Dublin 15, Ireland

Background: There is a role for shared care between rheumatologist and primary care for Musculoskeletal (MSK) disorders. General practitioners (GPs) are involved in monitoring of clinical status of patients and their management, in addition to psychosocial aspects of chronic pain and disability. We are going to look at the rheumatology knowledge and skills needed by local GPs and based on their needs we plan to develop an initiative to improve the service provided to our patients. Here are the results of the initial survey of local GPs.

Objectives: We aim to identify knowledge and skill gaps in primary care related to MSK disorders and to develop a need-based curriculum to address these gaps. Develop an implementation plan to deliver the curriculum components.

Methods: Initially we identify the needs and gaps in the current practice using survey in a small group of local GPs. There are two rounds of questionnaires to reach a list of important areas to develop the curriculum. The second round will include large number of GPs. Also, there will be meetings with GPs to reach agreement and to adopt method of delivering these training and skills.

Results: In the first survey, 31 out of 36 GPs (86\%) returned questionnaires. One GP $(3.2 \%)$ refer to rheumatology department twice a week, 4 GPs $(13 \%)$ refe weekly, 23 GPs (74\%) refer every month and three GPs $(9.7 \%)$ rarely refer to rheumatologist. Reasons for referral were diagnosis and long-term management, ${ }^{21}$ diagnosis and discharge back to $\mathrm{GP}^{15}$ and patient's request. ${ }^{4}$ Thirteen GPs $(42 \%)$ have interest in rheumatology conditions management. Regarding GPs' concerns with rheumatology service, 22 of them (71\%) mentioned the long wait time for rheumatology appointment. Other issues were delayed clinic letter, need for clear instruction, patients not aware of appointment time, whether there is an urgent clinic and which clinic patient should be referred to (outpatient versus procedure clinics). Nineteen GPs (61\%) received undergraduate rheumatology training, $16(52 \%)$ during GP training programme and $4(13 \%)$ attended postgraduate courses. Topics of interest by GPs were variable rheumatology conditions in addition to joint injections, ${ }^{3}$ referral guidance ${ }^{2}$ and update on DMARD. Preferred teaching methods to deliver the syllabus were small group tutorials, ${ }^{12}$ face-to-face lectures $^{8}$ and protocols and guidelines. ${ }^{5}$

Conclusions: From this initial survey, we could identify that the major concern of local GPs is the long waiting time for rheumatology clinic. Some of GPs $(42 \%)$ expressed their interest to have further training in rheumatology. When we reach an agreed curriculum with GPs, we aim to deliver the syllabus through preferred methods by GPs. Shared care between rheumatologists and GPs would improve quality standard of care in community, provide patient care close to home and reduce referral rates. 


\section{REFERENCES:}

[1] Teaching rheumatology in primary care, Ann Rheum Dis. 2000, G. Hosie.

[2] Musculoskeletal education in US medical schools:lessons from the past and suggestions for the future, Curr Rev Musculoskelet Med.2011, Seetha U. Monrad.

[3] Development of a competency framework for general practitioners with a special interest in musculoskeletal/rheumatology practice, Rheumatology 2007, E. M. Hay.

[4] Assessing the Need for Improved Access to Rheumatology Care: A Survey of Massachusetts Community Health Center Medical Directors, J Clin Rheumatol, 2013.

Disclosure of Interest: None declared

DOI: 10.1136/annrheumdis-2018-eular.6013

\section{AB1262 TAPERING OF BIOLOGICAL ANTIRHEUMATIC DRUGS IN RHEUMATOID ARTHRITISPATIENTS IS ACHIEVABLE AND COST EFFECTIVE IN DAILY CLINICAL PRACTICE: DATA FROM THE BRUSSELS UCL RA COHORT}

S. Dierckx, B. Lauwerys, T. Sokolova, L. Meric De Bellefon, M. Stoenoiu, A. Nzeusseu, F. Houssiau, A. Avramoska, P. Durez. Rheumatology, Cliniques universitaires Saint-Luc - Université Catholique de Louvain - Institut de Recherche Expérimentale et Clinique (IREC), Brussels, Belgium

Background: Several studies demonstrate that Rheumatoid Arthritis (RA) patients achieving low disease activity or remission are able to taper biological (b) DMARDs.

Objectives: The aim of this study is to determine the number of patients suffering from $R A$ in whom tapering of bDMARDs is achievable in daily practice and to evaluate the patient characteristics. Another objective is to analyse the budget impact and determine which bDMARDs are more adapted to dose reduction.

Methods: Inclusion criteria were RA patients from our Brussels UCL cohort treated with a bDMARD for at least one year. A dose reduction was proposed by the senior physician when sustained low disease activity or remission was observed. Data from 357 eligible RA patients ( 247 women and 110 men) were collected. Patient characteristics and baseline features before the current bDMARDs and flares if happened were collected. Annual drug dosage and cost were calculated.

Results: In 131 patients $(35.7 \%)$, the dose of the bDMARD could be tapered Patients in the decreased dose group were older ( 60.6 vs 55.9 years, $p=0.005$ ) and started bDMARDs earlier in their disease course ( 6.8 vs 8.4 years, $p=0.025$ ). As expected, the current DAS28-CRP was lower (2.26 vs $2.55, \mathrm{p}=0.018)$ and interestingly, more patients were treated with a combination of Methotrexate $(84 \%$ vs $73 \%, p=0.019$ ). No differences between groups was observed for gender, disease duration, baseline HAQ, DAS28-CRP, erosion, ACPA, number of previous bDMARDs and use of Glucocorticoïds. In our cohort, Anti-TNF agents were the most commonly prescribed medications (see Table). Annual drug cost was largely decreased for Rituximab and anti-TNF agents. Only 11 patients experienced a flare during the follow-up.

Abstract AB1262 - Table 1

\begin{tabular}{lccccc}
\hline bDMARD & $\begin{array}{c}\text { Number of } \\
\text { Pts }\end{array}$ & $\begin{array}{c}\text { Stable } \\
\text { dose }(\%)\end{array}$ & $\begin{array}{c}\text { Annual cost/ } \\
\text { Pts }(€)\end{array}$ & $\begin{array}{c}\text { Dose } \\
\text { decreased }(\%)\end{array}$ & $\begin{array}{c}\text { Annual cost/ } \\
\text { Pts }(€)\end{array}$ \\
\hline ABA & 23 & $12(52)$ & 12979 & $11(48)$ & 8643,5 \\
ADA & 46 & $21(46)$ & 12525 & $25(54)$ & 6908,8 \\
CERTO & 7 & $7(100)$ & 11740,2 & $0(0)$ & Not available \\
ETN & 69 & $41(59)$ & 9328,6 & $27(39)$ & 6101,6 \\
GOL & 24 & $22(92)$ & 12703,08 & $2(8)$ & Not available \\
IFX & 99 & $74(75)$ & 7290 & $25(25)$ & 6067 \\
RTX & 37 & $22(59)$ & 8784 & $17(46)$ & 4691,6 \\
TOC & 52 & $35(67)$ & 12773,7 & $17(33)$ & 9371,9 \\
& 357 & 234 & & 124 & \\
\hline
\end{tabular}

Conclusions: In daily practice, tapering of bDMARDs in RA patients with low disease activity or remission is an achievable goal, thereby reducing annual drug cost, especially for Rituximab, Infliximab, Etanercept and Adalimumab.

Disclosure of Interest: None declared

DOI: 10.1136/annrheumdis-2018-eular.6342

\section{AB1263 \\ FINNISH HEALTHVILLAGE.FI-RHEUMATICDISEASES.FI: A SPECIALISED CARE SERVICE UNIT DEVELOPED TOGETHER WITH PATIENTS TO OFFER ON-LINE INFORMATION AND TREATMENT FOR PATIENTS IN A MODERN WAY}

R.A. Luosujärvi ${ }^{1}$, K. Taimen ${ }^{2}$, S. Lindqvist ${ }^{1}$, R. Roiha ${ }^{1}$, O. Kaipiainen-Seppanen ${ }^{3}$,

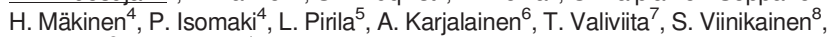
K. Eklund ${ }^{8}$, S. Arvonen ${ }^{1}$, on behalf of Finnish Helathvillage.fi-rheumaticdiseases.fi working team. ${ }^{1}$ Rheumatology virtual hospital, Helsinki university hospital, HUS, Helsinki; ${ }^{2}$ Turku University Hospital, Turku; ${ }^{3}$ Department of Rheumatology, Kuopio University Hospital, Kuopio; ${ }^{4}$ Department of Rheumatology, Tampere University hospital, Tampere; ${ }^{5}$ Department of Rheumatology, Turku University Hospital, Turku; ${ }^{6}$ Department of Rheumatology, Oulu University Hospital, Oulu; ${ }^{7} \mathrm{Helsinki}$ university hospital, Hyvinkaa; ${ }^{8}$ Department of Rheumatology, Helsinki university hospital, HUS, Helsinki, Finland

Background: Finnish on-line Health village environment, so-called HUS-MAPC was used to develop on-line information for rheumatic patients.

Objectives: To face the challenge of increasing demand for rheumatological care without additional resources a new virtual client-orientated service was developed.

Methods: In Finland, an on-line Health village environment, so-called HUS MAP@, has been developed to offer virtual digital information to citizens, patients, and healthcare professionals. By using this HUS-MAPC environment, we provide information and support to citizens and patients who need information on differen rheumatic diseases and various unspecified aches and musculoskeletal pains The study group consisted of participants from every university hospital in Finland from local authorities; rheumatologists, other specialists, general practitioners, nurses, special professionals such as physical therapists, and patients. Information provided was based on updated international and Finnish guidelines on rheumatic diseases. After the information was reviewed and accepted by our study group, it was fed into a special program and published on-line in the Health village environment.

Results: E-service for citizens and patients was opened in March 2017. Detailed description of symptoms, diagnosis and therapy of various rheumatic diseases, such as rheumatoid arthritis, spondyloarthritis, connective tissue diseases and vasculitis are available. Early diagnosis and treatment to remission when possible is emphasised. The service aids to identify, by using symptom navigator and questionnaires for back pain, as well as swollen and painful joints those who may have a rheumatic disease and guide patients to find medical services without delay. Already 60500 persons have visited our website.

Conclusions: Finnish e-service, rheumaticdiseases.fi, offers an easy way to reach people and increase citizen's awareness on their own health. By guiding people to search for care the service may reduce delays in diagnosis of rheumatic diseases and the onset of therapy

Acknowledgements: To patients and healthcare professionals workin in Finnish Helathvillage.fi-rheumaticdisease.fi

Disclosure of Interest: None declared

DOI: 10.1136/annrheumdis-2018-eular.1034

\section{AB1264 \\ BARRIERS AGAINST TESTING ANTI-TNF DRUG LEVELS AND ANTI-DRUG ANTIBODIES IN ROUTINE CLINICAL} PRACTICE

S.P. Gavan ${ }^{1,2}$, G. Daker-White ${ }^{3}$, K. Payne ${ }^{2}$, A. Barton ${ }^{1,4} .{ }^{1}$ NIHR Manchester Biomedical Research Centre, Manchester University NHS Foundation Trust, Manchester Academic Health Science Centre; ${ }^{2}$ Manchester Centre for Health Economics; ${ }^{3} \mathrm{NIHR}$ Greater Manchester Primary Care Patient Safety Translational Research Centre; ${ }^{4}$ Centre for Musculoskeletal Research, The University of Manchester, Manchester, UK

Background: There is growing interest in using tests to measure anti-TNF drug levels and anti-drug antibodies (ADAb) in routine clinical practice for patients with rheumatic diseases. Testing may provide rheumatologists with additional information when considering a decision to adjust biologic treatment; for example, a decision to increase the interval between injections of an anti-TNF or to change treatment to a biologic that has a different target. However, it is not clear whether rheumatologists consider drug level and ADAb testing to be a useful technology within their routine clinical decision-making. Testing may be implemented imperfectly if rheumatologists perceive barriers against measuring drug levels and ADAb which, in turn, can affect the effectiveness and cost-effectiveness of care. Objectives: To explore the potential barriers against testing anti-TNF drug levels and ADAb in routine clinical practice.

Methods: Semi-structured telephone interviews were conducted individually with a purposive sample of consultant rheumatologists from different hospitals across England. The telephone interviews were recorded and transcribed verbatim. Pilot interviews were undertaken to develop the interview schedule. The rheumatologists were invited to discuss their perceptions and experiences of anti-TNF drug 